\title{
RESEARCH REVIEW ON AUGMENTED REALITY AS AN EDUCATIONAL RESOURCE FOR PEOPLE WITH INTELLECTUAL DISABILITIES
}

\author{
Marcos Gómez-Puerta \\ Universidad de Alicante \\ marcos.gomez@ua.es \\ Esther Chiner \\ Universidad de Alicante \\ Paola Melero-Pérez \\ Universidad de Alicante \\ Gonzalo Lorenzo Lledó \\ Universidad de Alicante
}

Fecha de Recepción: 22 Marzo 2019

Fecha de Admisión: 30 Abril 2019

\begin{abstract}
The present study reviewed nine publications related to the application of augmented reality (AR)-based interventions to people with intellectual disabilities (ID). The lines of research developed focus on the areas of education, personal autonomy and health promotion. The studies are theoretical frameworks, design of AR-based applications, or quasi-experimental study designs without a control group. The samples, all of less than 15 subjects, have been chosen under intentional criteria. The devices that seem to prevail as preferred for its application in this group are the portable ones due to the wide range of intervention possibilities that they offer as well as the development potential of the personal autonomy that they allow. Results offer a positive view of the application of this technology to people with ID, although the characteristics of the studies do not allow yet its generalization. Among the reported benefits are: enhancing learning achievement, motivation and enjoyment of tasks, helping to understand information, enhancing orientation, raising the level of engagement.
\end{abstract}

Keywords: augmented reality; intellectual and developmental disabilities; educational technology; research review

\section{INTRODUCTION}

The technological development that has occurred in the last decades has affected several areas, among which is education. The new advances in hardware and software as well as the training and didactic updating of teachers and the investment of educational centers in new media have produced 

DISABILITIES

the incorporation of technologies for communication and learning in the school environment. In parallel, the scientists have tried to evidence the applications and the most appropriate use of these teaching means as well as its concrete effects on student learning. One of the most innovative technological advances at present is augmented reality (AR). AR is software that allows combining the real world environment with objects or virtual information in such a way that the user perceives, either through mobile or non-mobile devices, those contents in a blended way (Azuma et al., 2001). Unlike virtual reality, the function of $A R$ is not to supplement the real world but to complement it.

Individuals with ID have limitations to understand information (written, oral or social) and to develop adaptive behaviors (practical, social and conceptual skills). Impairment of ID can range from mild levels to profound disability levels, showing a wide range of characteristics and needs. One of the essential aspects in the intellectual functioning of people with this type of disability is their difficulty in the process of learning and understanding of the information present in the environment, between which is the language, whether oral or written, or even social norms and rules that are implicit in the culture of each environment (Schalock et al., 2010). Even at mild levels of ID, the obstacles to such apprehension can be substantial, and it will be crucial to implement specific measures to facilitate their adequate perception of the information available in the context.

Among the different strategies used to respond to these needs, in recent years the use of information and communication technologies (ICTs)(e.g., computers, tablets, smartphones) is perceived as a particularly promising area for its possible benefits for these users regarding the potential training and functionalities offered by these devices (Hart et al., 2003; Molin et al., 2015). Centering again on $A R$, if research on the application of $A R$ in general education and attention to student diversity is scarce, research on AR focused specifically on the education of people with intellectual and developmental disabilities is even meager. Though, the development and research of AR is of particular interest to this group as it could provide benefits such as self-determination and support for selfmanagement, guidance through self-instruction in complex tasks resolution (Ayres, Mechling, \& Sansosti, 2013), or guidance and location in various environments (McMahon, Cihak, \& Wright, 2015). In this sense, the purpose of the present study is to analyze and systematize the main research carried out in the application of the AR to students with ID in order to offer a summary of available evidence and research areas developed, while reflecting on current trends and future lines of research. Specifically, the objectives $(0)$ and research questions $(R Q)$ of this review are:

01: Describe the main studies on the application of AR to people with ID.

RQ1: What was the purpose of the studies?

RQ2: What type of AR was used in the studies?

RQ3: What was the design and sample size used?

02: Describe the research lines developed so far and its main results

RQ4: What were the areas of research addressed?

RQ5: What was the reported effectiveness of AR?

\section{METHOD}

There are several methods for undertaking a systematic review of published empirical literature (eg, selecting articles from only the most prestigious journals in a specific field of knowledge by applying one or more selection criteria (Hwang\& Tsai, 2011; Karata, 2008; Nolen, 2009), searching databases where studies are indexed (Drysdale et al., 2013; Kuccuk et al., 2013)). In the present study, we followed the instructions proposed by Kitchenham (2004), which are composed by three 
consecutive steps: (a) planning (selection of journals, definition of inclusion and exclusion criteria of studies, and definition of categories for the analysis), (b) conducting the review (study selection, data extraction, data synthesis and data coding), and (c) reporting the review (analysis of results, discussion of findings, trends and conclusions). We also considered the recommendations made in the Preferred Reporting Items for Systematic Review and Meta-analysis Protocols (PRISMA-P) 2015 Statement (Moher et al., 2015).

\section{Planning the review: literature research strategy}

As indicated above, due to the scarcity of studies, we decided not to focus specifically on research published in journals but also to accept papers presented at meetings or congresses. Document search was performed using the Web of Knowledge provided by the Institute for Scientific Information (ISI), using the Science Citation Index (SCI) and Social Sciences Citation Index (SSCI) databases. The following inclusion and exclusion criteria were established:

Table 1

Inclusion and exclusion criteria

\begin{tabular}{|c|c|c|}
\hline $\begin{array}{l}\text { General } \\
\text { criteria }\end{array}$ & $\begin{array}{l}\text { Specific } \\
\text { criteria }\end{array}$ & Exclusion criteria \\
\hline $\begin{array}{l}\text { a) Research studies } \\
\text { articles } \\
\text { b) Meeting } \\
\text { communications based on } \\
\text { research studies } \\
\text { c) Theoretical frameworks } \\
\text { with potential research } \\
\text { applications }\end{array}$ & $\begin{array}{l}\text { Presence of the } \\
\text { concepts (1) augmented } \\
\text { reality, and (2) ID and / } \\
\text { or mental retardation. }\end{array}$ & $\begin{array}{l}\text { 1) Documents belonging to the } \\
\text { following areas of knowledge: } \\
\text { communication, food technology, } \\
\text { mathematics, neuroscience and } \\
\text { demography. } \\
\text { 2) Documents that referred to } \\
\text { disability or inclusion in general, or } \\
\text { referred in general to learning } \\
\text { disabilities. }\end{array}$ \\
\hline
\end{tabular}

When the search was made about AR and disability, a total of 115 documents were found, of which 42 were articles and 73 papers presented at meetings. Of these, and when a more specific search was made with the presence criteria of AR and ID in the title or subject, only 7 studies were found that met the inclusion criteria. Secondly, a search for AR and mental retardation was carried out, which offered 2 valid documents, reaching a total of 9 studies that met the inclusion criteria, which are those indicated in table 2 below. 
Table 2

Selected studies for this review

\begin{tabular}{ll}
\hline Selected studies & Countries \\
\hline Chang, Kang, \& Huang (2013). & China \\
\hline Colpani, \& Petrucelli, (2016). & Brazil \\
\hline Covaci, Kramer, Augusto, Rus, \& Braun (2015). & $\begin{array}{l}\text { Germany, United } \\
\text { Kingdom }\end{array}$ \\
\hline Heyn, Baumgardner, McLachlan, \& Bodine (2014). & USA \\
\hline McMahon (2014). & USA \\
\hline McMahon, Cihak, Gibbons, Fussell, \& Mathison (2013). & USA \\
\hline Ramli \& Zaman (2011). & India \\
\hline Tenemaza, De Antonio, Ramirez, Vela, \& Rosero (2016). & Ecuador \\
\hline Vullamparthi, Nelaturu, Mallaya, \& Chandrasekhar (2013). & India \\
\hline
\end{tabular}

\section{Data evaluation, reduction and analysis}

Each localized document that met the specified inclusion criteria was analyzed individually again to verify that it actually conformed to them. In the first analysis, each member of our group examined the studies to suggest possible categories of analysis depending on the characteristics of the research and the investigation objectives of our study. Subsequently, our group reached consensus on the categories of analysis, which are by which the results are presented below. The coding of the data was done, firstly, by creating a summary table of the studies and, second, by content analysis of each document, creating a brief description of the study and its main results.

\section{RESULTS}

Results are presented below according to the research questions of this study.

\section{Main studies on the application of AR to people with ID}

Next, we analyze the results related to the purpose of the studies, type of AR used, and type of design and sample.

\section{RQ1: What was the purpose of the studies?}

The research purposes of the analyzed works covered various aspects of intervention. In the first place, one of the most outstanding aspects is the application of the AR to the orientation of people with ID, which was addressed by three of the studies reviewed. These studies applied to (a) orientation in real environments to locate specific milestones and encourage autonomous movement through the city (McMahon, 2014), (b) ask for help and show the location in case of danger or disorientation (Tenemaza et al., 2016), and (c) training for orientation and recognition of landmarks in the environment (Covaci et al., 2015).

Second, the educational field also caught the interest of five other studies. Specifically, two of 
them established frameworks for the design or evaluation of educational activities for people with ID. Ramli \& Zaman (2011) established a usability evaluation method of AR basic reading courseware, while Colpani \& Petrucelli (2016) proposed a design framework for educational activities based on gamification (i.e., activities adapted to the mechanics of a game). Chang et al. (2013) designed and implemented a AR-based vocational task prompting system which used picture cues in order to guide users through successive steps. This help allowed users to identify mistakes and make the appropriate corrections. Vullamparthi et al. (2013) used a QR codes-marker-based AR android mobile application to develop visual schedulers, speaking picture albums, a 3D picture association tool, and a functional reading creation tool specifically for the help of children with autism and mild intellectual disability. In this same sense, McMahon (2014) also made a research based on an intervention for vocabulary instruction for science terms based on AR.

The third group of research purposes is related to the field of health. On the one hand, AR was used as a strategy for motivation and involvement in the tasks of a rehabilitation program based on physical exercise (i.e., biking, walking)(Heyn et al., 2014). On the other hand, McMahon et al. (2013) used the Red Laser App to promote cognitive accessibility to food labeling information in supermarkets for people with ID with allergies to foods. This intervention was carried out in order that these people could identify the presence of allergens in certain foods before buying and/or consuming them.

\section{RQ2: What type of AR was used in the study?}

Regarding the type of AR used in the studies, the frameworks for the design and/or evaluation of educational activities mentioned above (Colpani \& Petrucelli, 2016; Ramli \& Zaman, 2011) and the AR-based vocational skills training method (Chang et al., 2013) are especially oriented to stationary devices in a classroom or workplace context. Other studies used the stationary AR for the initial training of the participants in certain tasks, such as orientation in the environment through virtual navigation. However, this type of interventions used portable AR in a second moment, in order to evaluate the effectiveness of both training and the use of portable devices with AR for orientation in real contexts (Covaci et al., 2015). However, most studies analyzed $(n=5 ; 55 \%)$ used AR using portable devices (Heyn et al., 2014; McMahon, 2014; McMahon et al., 2013; Tenemaza et al., 2016; Vullamparthi et al., 2013).

Figure 1. Type of AR devices used in the reviewed studies according to its portability.

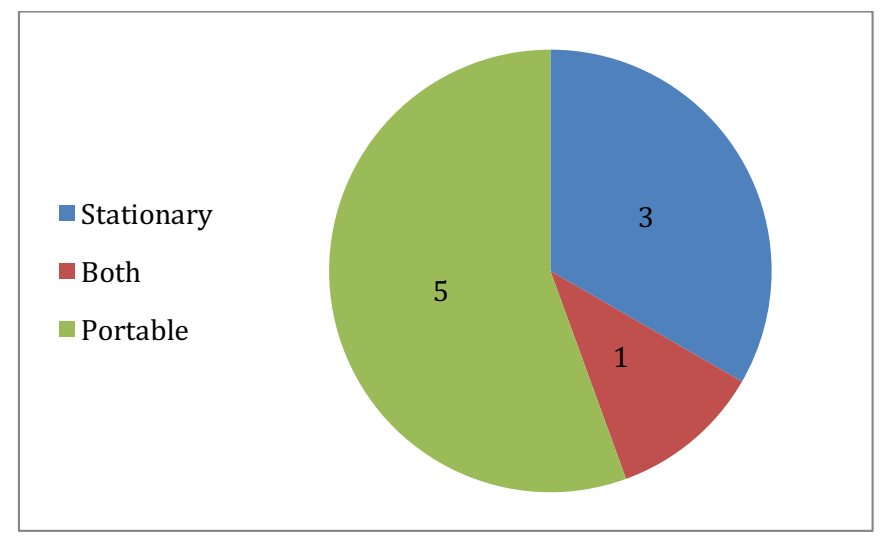




\section{RQ3: What was the design and sample used?}

As can be seen in Table 3, most studies used experimental designs to conduct the investigations, although they did not have a control group with which to compare the results of the interventions.

Regarding size, all the works reviewed had a sample of less than 15 subjects. Although in most cases it is not specifically indicated, it is understood that the selection of samples was made through non-probabilistic procedures and intentional methods, prioritizing the selection of participants that met certain criteria.

\section{Table 3}

Type of research design and sample size used

\begin{tabular}{|c|c|c|}
\hline Study & Design & Sample \\
\hline Chang, Kang, \& Huang (2013). & Multiple probe design & $\begin{array}{l}\text { Three } \\
\text { participants: two } \\
\text { with moderate ID, } \\
\text { one with severe } \\
\text { ID. }\end{array}$ \\
\hline Colpani \& Petrucelli (2016). & $\begin{array}{l}\text { The development } \\
\text { methodology chosen for the } \\
\text { prototype framework was } \\
\text { the generic model of } \\
\text { software called } \\
\text { Evolutionary Development. }\end{array}$ & Theoretical. \\
\hline $\begin{array}{l}\text { Covaci, Kramer, Augusto, Rus, } \\
\text { \& Braun (2015). }\end{array}$ & $\begin{array}{l}\text { Preliminary study with } \\
\text { Experimental methodology } \\
\text { (without control group). }\end{array}$ & $\begin{array}{l}\text { Thirteen } \\
\text { participants with } \\
\text { DS participated in } \\
\text { the study. The } \\
\text { mean age of the } \\
\text { group was } 26.4 \\
\text { years (SD }=3.12) \text {. } \\
\text { There were } 5 \text { men } \\
\text { and } 8 \text { women in } \\
\text { the group with }\end{array}$ \\
\hline & & $\begin{array}{l}\text { different levels of } \\
\text { cognitive } \\
\text { disability. }\end{array}$ \\
\hline $\begin{array}{l}\text { Heyn, } \quad \text { Baumgardner, } \\
\text { McLachlan, \& Bodine (2014). }\end{array}$ & $\begin{array}{l}\text { Cross-sectional, } \\
\text { observational pilot study }\end{array}$ & $\begin{array}{l}\text { Six participants: } 2 \\
\text { had Spinal Cord } \\
\text { Injury, } 2 \text { had } \\
\text { Intellectual and } \\
\text { Developmental } \\
\text { Disabilities, and } 2 \\
\text { had no disability. }\end{array}$ \\
\hline
\end{tabular}




\begin{tabular}{|c|c|c|}
\hline McMahon (2014). & $\begin{array}{l}\text { Experimental } \\
\text { without control group (study } \\
\text { 1: multiple probe across } \\
\text { skills design; study 2: } \\
\text { alternating } \\
\text { design). }\end{array}$ & $\begin{array}{l}\text { Sample } 1 . \\
\text { Four individuals } \\
\text { with ID and } \\
\text { autism } \\
\text { Sample } 2 . \\
\text { Four individuals } \\
\text { with ID and } \\
\text { autism spectrum } \\
\text { disorder. }\end{array}$ \\
\hline $\begin{array}{l}\text { McMahon, Cihak, Gibbons, } \\
\text { Fussell, \& Mathison (2013). }\end{array}$ & ABAB design & $\begin{array}{l}\text { Seven individuals } \\
\text { with ID } \\
\text { participated. }\end{array}$ \\
\hline Ramli \& Zaman (2011). & $\begin{array}{l}\text { Theoretical framework and } \\
\text { a case study }\end{array}$ & $\begin{array}{l}\text { Theoretical } \\
\text { framework / One } \\
\text { student with } \\
\text { Down Syndrome. }\end{array}$ \\
\hline 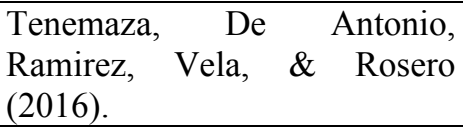 & $\begin{array}{l}\text { Experimental design with a } \\
\text { questionnaire about the } \\
\text { usability of the app. }\end{array}$ & $\begin{array}{l}\text { Ten users with } \\
\text { ID. }\end{array}$ \\
\hline $\begin{array}{l}\text { Vullamparthi, } \begin{array}{l}\text { Nelaturu, } \\
\text { Mallaya, \& Chandrasekhar } \\
\text { (2013). }\end{array}\end{array}$ & $\begin{array}{l}\text { Development of a } \\
\text { multifunctional Android } \\
\text { application for children with } \\
\text { autism spectrum disorder } \\
\text { and intellectual disability. }\end{array}$ & $\begin{array}{l}\text { Preliminary use in } \\
12 \text { special schools } \\
\text { in Andhra } \\
\text { Pradesh and } \\
\text { Bangalore (India). }\end{array}$ \\
\hline
\end{tabular}

\section{Research lines developed so far and its main results}

In this section we will describe, on the one hand, the main lines of research developed and, on the other hand, the evidence on the effectiveness of the interventions carried out.

\section{RQ4: What were the areas of research addressed?}

If we group the reviewed publications according to the purpose of the proposed interventions, we can establish three clearly delimited lines of research. First, most studies focus on the field of education proposing interventions for vocational skills training (Chang et al., 2013), design of activities based on gamification (Colpani \& Petrucelli, 2016), acquisition of vocabulary (McMahon, 2014), improving reading competence (Ramli \& Zaman, 2011; Vullamparthi et al., 2013), routine following, completing tasks or generalization of concepts (Vullamparthi et al., 2013). Secondly, research aimed at favoring the personal autonomy of individuals with ID by means of AR that facilitates orientation in real environments for the location of places (Covaci et al., 2015; McMahon, 2014), communication of our location at a specific time, or request for help in case necessary (Tenemaza et al., 2016). Third, a line of work oriented towards the health of people with ID is identified. On the one hand, risk prevention is favored by the identification of allergens in food (McMahon 
et al., 2013) and, on the other, engagement in programs based on physical rehabilitation tasks is favored (Heyn at al., 2014).

Table 4

Current lines of research on intervention in people with ID using $A R$

\begin{tabular}{|c|c|c|}
\hline Research line & Study & Specific areas \\
\hline \multirow{6}{*}{ Education } & Chang et al. (2013). & Vocational skills training \\
\hline & Colpani \& Petrucelli (2016). & Gamification of activities \\
\hline & McMahon (2014). & Learning of vocabulary \\
\hline & Ramli \& Zaman (2011). & Learning to read \\
\hline & Vullamparthi et al. (2013). & \\
\hline & Vullamparthi et al. (2013). & $\begin{array}{l}\text { Routine following, } \\
\text { completing tasks, } \\
\text { generalization of concepts. }\end{array}$ \\
\hline \multirow{3}{*}{ Navigation, travel, location } & Covaci, et al. (2015). & Orientation \\
\hline & McMahon (2014). & Autonomy to travel \\
\hline & Tenemaza et al. (2016). & Location, ask for help. \\
\hline \multirow[b]{2}{*}{ Health } & Heyn et al. (2014). & $\begin{array}{l}\text { Engagement and motivation } \\
\text { towards exercise trials. }\end{array}$ \\
\hline & McMahon et al. (2013). & $\begin{array}{l}\text { Identification of allergens in } \\
\text { packaged foods. }\end{array}$ \\
\hline
\end{tabular}

\section{RQ5: What was the reported effectiveness of AR?}

Taken together, all the studies cited provide a positive view of RA as an intervention resource for people with ID in the various areas analyzed based on the outcomes achieved. Among the general aspects that most stand out the authors, it is necessary to indicate the motivation and implication in the task due to the use of this new technology. Likewise, all the studies emphasize the importance of this incipient line of research and conclude that it will significantly favor the intervention for the improvement of the teaching and learning process, and the personal autonomy of this group in the coming years. As a summary of findings, we reflect the main results achieved in the investigations reviewed in the following table. 
Table 5

Summary of findings of the researches reviewed

\begin{tabular}{ll}
\hline Study & Summary of findings \\
\hline Chang, Kang, \& Huang (2013). & $\begin{array}{l}\text { All participants improved their success rates and } \\
\text { maintained their acquired skills during the } \\
\text { maintenance phase. The ARCoach system in } \\
\text { conjunction with operant conditions strategies } \\
\text { may facilitate autonomous functioning in } \\
\text { vocational jobs. }\end{array}$ \\
\hline Colpani \& Petrucelli (2016). & $\begin{array}{l}\text { The framework helps the learning process of } \\
\text { children with } \\
\text { ID in general through interaction between the } \\
\text { individual and the object by stimulating } \\
\text { curiosity, initiative and active participation. }\end{array}$ \\
\hline Covaci, Kramer, Augusto, Rus, \& & $\begin{array}{l}\text { The users have improved their results when } \\
\text { repeatedly } \\
\text { faced with the challenge of learning a route. } \\
\text { Moreover, when adding the AR component, our } \\
\text { solution could provide the cognitive disabled } \\
\text { user with important, useful contextual } \\
\text { information for spatial cognition including } \\
\text { landmarks also when she/he is outside. }\end{array}$
\end{tabular}

Heyn, Baumgardner, McLachlan, \& Participants'feedback suggested that the MR Bodine (2014). environment could be entertaining, motivating, and engaging for users with disabilities, resulting in a foundation for further development of this technology for use in individuals with cognitive and physical disabilities.

McMahon (2014). $\quad$ The marker-based AR features were responsible for the positive outcomes without distracting the learner.

AR instruction has the potential to become a particularly powerful medium for students and people with disabilities because the capability of displaying context relevant digital information to support the needs of the individual at that moment. 
McMahon, Cihak, Gibbons, Fussell, The skills developed by the students using these \& Mathison (2013). mobile devices persist wherever they have the device and need to use it. The results demonstrated that there was an immediate improvement in making the correct choice relating to specific foods and possible allergens using the Red Laser App.

Ramli \& Zaman (2011).

The evaluation methods discussed will be provided as guidance to do the usability evaluation that involves special needs children such as Down Syndrome children.

Tenemaza, De Antonio, Ramirez, Augmented Reality has proved to be a useful Vela, \& Rosero (2016). alternative to provide information, but elderly and disabled people need to get familiar with this new technology.

Vullamparthi, Nelaturu, Mallaya, \& Development of an Android app for the use of a Chandrasekhar (2013). visual scheduler, a speaking album, AR based 3D picture association took and a functional reading creation tool. It has been implemented at 12 special schools in India, as part of the eSaadhya project implementation framework.

\section{DISCUSSION}

The purpose of this study was to analyze and systematize the main research carried out in the application of the AR to students with ID in order to offer a summary of available evidence and research areas developed, while reflecting on current trends and future lines of research.

Regarding the main studies on the application of AR to people with ID, we found works oriented to the design of theoretical frameworks for the design or evaluation of educational activities, or interventions for the development of the learning potential and personal autonomy of individuals with ID. The devices most used for AR intervention are mobile devices, especially smartphones, due to their price, accessibility and social inclusion in their use. This fact is relevant since several studies have shown that the device most commonly used by people with ID is the smartphone (Didden et al., 2009; Chiner, Gómez \& Cardona, 2017; Gutiérrez \& Martorell, 2011).

Thus, AR used through mobile devices allows the possibility of providing information of the environment to the person with ID of which he or she may not be aware independently. In this sense, and as defined by McMahon (2014), AR could fulfill a function of "cognitive prosthesis". This technical assistance would facilitate the cognitive accessibility of these people to the different environments, as it would make them more intelligible or easy to understand. This measure is a key to favor the emotional well-being of the subject, since the environments that are understandable make them 
more easily predictable, improve our sense of control over them and also favor our participation (Belinchón, Casas, Díez and Tamarit, 2014).

However, in general, all of the reviewed researches show weaknesses in their design regarding the control of certain variables. For example, the degree of disability or adaptive behaviors of the participants was not adequately controlled, mixing different levels of these traits. Likewise, the prerequisites for the effective use of the devices used were not always established and/or measured. Finally, the overlap of autism spectrum disorders and ID (McMahon, 2014; Vullamparthi et al., 2013) or of ID and physical disability (Heyn et al., 2014) in the sample, as well as the fact that two studies specifically focus on individuals with ID derived from an etiology specific as Down syndrome (Covaci et al., 2015; Ramli \& Zaman, 2011) or that, in addition, most studies focus on children and young people with ID make it difficult to extrapolate or generalize the results specifically in the group of reference.

Regarding the lines of research developed, the first aspects addressed in the scientific field coincide with those aspects most relevant to the life of any person and, especially, in the case of people with ID: education, personal autonomy and health. The results achieved so far offer a positive and optimistic perspective towards the future development of this technology and its applications for this group. Consistent with those highlighted by Akçayir \& Akçayir (2017) regarding the use of AR in educational settings, the studies analyzed report as advantages of AR enhancing learning achievement, enhancing learning motivation, helping to understand information, enhancing orientation, enhancing enjoyment, raising the level of engagement in the task, increasing interest, and enabling visualization of invisible information, among others.

\section{CONCLUSIONS}

The present study analyzed nine publications related to the application of AR-based interventions to people with ID. This is an emerging research field for which there is little scientific evidence. The published studies are still very scarce and should be developed in greater depth in the future.

The lines of research developed focus on the areas of education, personal autonomy and health promotion. The studies developed start from quasi-experimental designs without a control group. The samples, all of less than 15 subjects, have been chosen by non-probabilistic methods and under intentional criteria. The devices that seem to prevail as preferred for their application in this group are the portable ones due to the wide range of intervention possibilities that they offer as well as the development potential of the personal autonomy that they allow.

Among the reported benefits are: enhancing learning achievement, enhancing learning motivation, helping to understand information, enhancing orientation, enhancing enjoyment, raising the level of engagement in the task, increasing interest, and enabling visualization of invisible information. The results offer a positive view of the application of this technology to people with ID, although the characteristics of the studies do not yet allow its generalization. The application of AR to people with ID is an emerging research field for which there is little scientific evidence. The published studies are still very scarce and should be developed in greater depth in the future.

\section{REFERENCES}

Akçayir, M., Akçayir, G. (2017). Advantages and challenges associated with augmented reality for education: A systematic review of the literature. Educational Research Review, 20(1), 1-11. Doi. https://doi.org/10.1016/i.edurev.2016.11.002

Azuma, R., Baillot, Y., Behringer, R., Feiner, S., Julier, S., \& MacIntyre, B. (2001). Recent advances in augmented reality. IEEE Computer Graphics and Applications, 21(6), 34-47. Doi. 
10.1109/38.963459.

Belinchón, M., Casas, S., Díez, C. \& Tamarit, J. (2014). Accesibilidad cognitiva en centros educativos. Madrid: Ministerio de Educación, Cultura y Deporte.

Chang, K.-E., Chang, C.-T., Hou, H.-T., Sung, Y.-T., Chao, H.-L., \& Lee, C.-M. (2014). Development and behavioral pattern analysis of a mobile guide system with augmented reality for painting appreciation instruction in an art museum. Computers \& Education, 71(1), 185-197. doi:10.1016/j.compedu.2013.09.022

Chang, Y., Kang, Y., \& Huang, P. (2013). An augmented reality (AR)-based vocational task prompting system for people with cognitive impairments. Research in Developmental Disabilities, 34, 3049-3056.

Chiner, E., Gómez-Puerta, M., \& Cardona-Moltó, C. (2017). Internet use, risks and online behavior: The view of Internet users with ID and their caregivers. British Journal of Learning Disabilities, 45, $190-197$.

Colpani, R. \& Petrucelli, M. R. (2015). An innovative augmented reality educational framework with gamification to assist the learning process of children with intellectual disabilities, In Proceedings of the 6th International Conference on Information, Intelligence, Systems and Applications (IISA)(pp. 1-6). doi: 10.1109/IISA.2015.7387964.

Covaci, A. Kramer, D. Augusto, J.C., Rus, S., \& Braun, A. (2015). Assesing real world imagery in virtual environments for people with cognitive disabilities. In Proceedings of the 2015 International Conference on Intelligent Environments (pp. 41-48).

Didden, R., Scholte, R. H. J., Korzilius, H., De Moor, J. M. H., Vermeulen, A., O’Reilly, M., \&amp; Lancioni, G. E. (2009). Cyberbullying among students with intellectual and developmental disability in special education settings. Developmental Neurorehabilitation, 12(3), 146-151. https://doi.org/10.1080/17518420902971356.

Drysdale, J. S., Graham, C. R., Spring, K. J., \& Halverson, L. R. (2013). An analysis of research trends in dissertations and theses studying blended learning. The Internet and Higher Education, 17(1), 90-100. Doi. https://doi.org/10.1016/j.iheduc.2012.11.003

Gutiérrez, P. \& Martorell, A. (2011) People with ID and ICTs. Comunicar, 18, 173-180. D0I: 10.3916/C36-2011-03-09

Hart T., O'Neil-Pirozzi T., \& Morita, C. (2003) Clinician expectations for portable electronic devices as cognitive-behavioural orthoses in traumatic brain injury rehabilitation. Brain Injury, 17, 401411. DOI: http://dx.doi.org/10.1080/0269905021000038438

Heyn, P. C., Baumgardner, C. A., McLachlan, L. \& Bodine, C. (2014). Mixed-reality exercise effects on participation of individuals with spinal cord injuries and developmental disabilities: a pilot study. Top Spinal Cord Injuries Rehabilitation, 20(4), 338-345.

Hwang, G. J., \& Tsai, C. C. (2011). Research trends in mobile and ubiquitous learning: A review of publications in selected journals from 2001 to 2010. British Journal of Educational Technology, 42(4), 65-70.

McMahon (2014). Augmented Reality on Mobile Devices to Improve the Academic Achievement and Independence of Students with Disabilities (doctoral thesis). University of Tenessee, Knoxville, USA.

McMahon, D.D., Cihak, D.F., Gibbons, M.M., Fussell, L., \& Mathison, S. (2013). Using a mobile app to teach individuals with intellectual disabilities to identify potencial food allergens. Journal of Special Education Technology, 28(3), 21-32.

Moher, D. Shamseer, L., Clarke, M., Ghersi, D., Liberati, A., Petticrew, M., Shekelle, P., Stewart, L.A., \& PRISMA Group (2015). Preferred Reporting Items for Systematic Review and Meta-analysis 
Protocols (PRISMA-P) 2015 Statement. Systematic Reviews, 4(1), 1-9. doi: 10.1186/20464053-4-1

Molin M., Sorbring, E. \& Löfgren-Martenson, L. (2015). Teachers' and parents' views on the Internet and social media usage by pupils with intellectual disablities. Journal of Intellectual Disabilities, 19, 22-33. doi: 10.1177/1744629514563558

Nolen, A. L. (2009). The content of educational psychology: An analysis of top ranked journals from 2003 through 2007. Educational Psychology Review, 21(3), 279-289.

Schalock, R. L., Borthwick-Duffy, S. A., Bradley, V., Buntix, W. H. E., Coulter, M. D., Craig, E. M., Gomez, S. C., Lachapelle, Y., Luckasson, R., Reeve, A., Shogren, K. A., Snell, M. E., Spreat, S., Tassé, M. J., Thompson, J. R., Verdugo, M. A., Wehmeyer, M. L., \& Yeager, M. H. (2010). Intellectual Disability. Definition, Classification, and Systems of Supports. Washington: American Association on Intellectual and Developmental Disabilities (AAIDD).

Tenemaza, M., de Antonio, A., Ramírez, A., Vela, A., \& Rosero, D. (2016). Adaptive Augmented Reality in Mobile Applications for Helping People with Mild Intellectual Disability in Ecuador. In Proceedings of the $12^{\text {th }}$ International Conference on Web Information Systems and Technologies (WEBIST 2016)(vol. 2)(pp. 317-324). doi:10.5220/0005862203170324.

Vullamparthi, A.J., Nelaturu, S.C.B., Mallaya, D.D., \& Chandrasekhar, S. (2013). Assistive learning for children with autism using augmented reality. Speaking albums and visual auditory schedulers. In Proceeding of the 2013 IEEE Fifth International Conference on Technology for Education (pp. 43-46). doi: 10.1109/T4E.2013.18 
